\title{
Perspective: Catalytic Increase of Biogas Production in an Anaerobic Co-Digestion System
}

\author{
Sung Hee Joo'", Lucas Delicio², Jonathan Muniz² and Soyoung Baek \\ ${ }^{1}$ Department of Civil, Architectural, and Environmental Engineering, University of Miami, USA \\ ${ }^{2}$ Department of Biological Sciences, Florida International University, USA
}

\begin{abstract}
The use of iron nanoparticles (NPs) has proven attractive due to the NPs' abundance, non-toxicity, and cost effectiveness. However, there is a significant literature gap in biogas-production kinetics based on the addition of iron in the presence and in the absence of organic wastes in an anaerobic co-digestion system, despite the potential advantages of using iron to enhance the decomposition of organic substrates, thereby increasing biogas production. Addition of iron additives to a co-digestion system could considerably increase biogas production with greater chemical oxygen demand removal compared to a co-digestion system without iron additives (the control), thus increasing the co-digestion system's microbial activity compared to that of the control. Similarly, more production of biogas from a co-digestion system containing pretreated waste sludge (e.g. biosolids) and cow manure can occur because of the addition of iron additives. Iron-containing wastes can be utilized to increase biogas production as a catalyst in co-digestion of organic wastes. This perspective is used to address possible application of novel waste materials and environmentally sustainable nanomaterials such as green tea-extracted iron, which both contain iron, to organic wastes in an anaerobic co-digestion system for the efficacy of biogas production, along with a discussion of further research directions.
\end{abstract}

Keywords

Shotblast dust, Green tea-extracted iron, Co-digestion, Organic wastes, Biogas

\section{Introduction}

Recovering renewable energy through waste treatment processes can improve operation efficacy. Anaerobic digestion ( $\mathrm{AD}$ ), one of the most cost-effective processes of biomass to biogas conversion, has been widely applied for its multiple advantages in areas such as renewable energy production, the conservation of landfill space [1-4], and lower the resultant costs while contributing to the minimization of greenhouse gas emissions. Due to the growing generation of municipal solid waste (MSW) and biosolids, attention to alternative strategies to treat and manage MSW and biosolids has intensified. However, there are a number of issues associated with $\mathrm{AD}$ and its operation [5-
7]. First, sudden changes in temperature during the process are the major issue, as they influence the overall performance of the AD process. Although the literature indicated that the $\mathrm{AD}$ process needs to maintain a consistent mesophilic condition between $32^{\circ} \mathrm{C}$ and $35^{\circ} \mathrm{C}\left(90^{\circ} \mathrm{F}\right.$ and $95^{\circ} \mathrm{F}$ ) [8], $\mathrm{AD}$ can be operated at $20-55^{\circ} \mathrm{C}$ and different temperatures can influence microbial groups and formation of byproducts. A high temperature range could result in more rapid sludge reduction and methane generation, but it does not necessarily bring better outcomes. As an example, with nitrogenous residues, there is inhibition of the process in the thermophilic range due to the formation of ammonia.

${ }^{*}$ Corresponding author: Sung Hee Joo, Department of Civil, Architectural, and Environmental Engineering, University of Miami, 1251 Memorial Dr. McArthur Engineering Building, Coral Gables, FL 33146-0630, USA, Tel: +1305-284-3489, Fax: +1-305-284-3492, E-mail: s.joo1@miami.edu

Received: February 10, 2018: Accepted: April 26, 2018: Published: April 28, 2018

Copyright: (c) $2018 \mathrm{Joo} \mathrm{SH}$, et al. This is an open-access article distributed under the terms of the Creative Commons Attribution License, which permits unrestricted use, distribution, and reproduction in any medium, provided the original author and source are credited. 
Recent review studies have indicated that trace metals offer a critical role in $\mathrm{AD}$ performance, particularly in the stability of biogas digesters $[6,7,9]$. The study [9] indicated that the absence of trace metals in biogas digesters can be detrimental, leading to poor process efficiency regardless of suitable maintenance, such as controlling operational and environmental parameters. Thus, it is critical to investigate the role of trace elements in the $\mathrm{AD}$ process in order to overcome issues associated with $\mathrm{AD}$ and develop a sustainable way to generate renewable energy sources. Recent studies [10-12] showed that iron and $\mathrm{Fe}_{3} \mathrm{O}_{4}$ NPs were effective in generating more biogas, and the optimum concentration of both $\mathrm{Fe}$ and $\mathrm{Fe}_{3} \mathrm{O}_{4} \mathrm{NPs}$ was $20 \mathrm{mg} / \mathrm{L}$. There seems to be a significant benefit in adding iron (either Fe or iron oxide forms) to the anaerobic digester, but there is a significant literature gap regarding reaction mechanisms and kinetics as well as a lack of any further detailed studies on the effect of different types of iron nanoparticles (NPs), including waste iron. Iron synthesized with various types of tea extract (e.g., polyphenols acting as reducing and stabilizing agents) has been used in the removal of contaminants [13-15]. Polyphenols from various sources (e.g., tea, proteins, and vitamins), which have chemical structures of aromatic rings and hydroxyl groups and contribute to the synthesis of iron NPs, have been used due to their cost effectiveness and eco-friendly nature [16-18].

Among various sources, recent studies found greentea polyphenol extract to be the most promising reducing and capping agent with a superior degradation of contaminants [19-23] Such effective iron NPs can accelerate digestion of organic biomass, thereby producing more biogas. Thus, green tea-extracted iron NPs (GT-Fe) is one of iron additives that can be used to understand iron additives' influence on biogas production. As another iron additive, steel industry byproducts containing iron and iron oxides can be applicable as a catalyst to increase biogas production. In this study, perspective of the efficacy of iron additives (e.g., as a form of a waste byproduct produced from the US Foundry or a greentea extract) in accelerating degradation of organic wastes and increasing biogas production in an anaerobic digestion system is discussed.

This perspective study aims to discuss the efficacy of iron additives as a catalyst to enhance biogas production in co-digestion of organic wastes and to identify applicability of the waste byproduct (shotblast dust: SB), which is otherwise landfilled, as a resource for a rapid breakdown of organic wastes.

The Role of Iron NPs on Biogas and Methane Production of the Anaerobic Co-Digestion System

The co-digestion of multiple substrates, including co-digestion of biosolids and organic fraction of municipal solid waste, have proven to be effective in the performance of $\mathrm{AD}$ due to synergisms in the digestion medium, greater stability, a more voluminous supply of nutrients, reductions of ammonia inhibition, and economic advantages [24-29]. While co-digestion has also shown improved nutrient balance and digestion, as well as additional biogas production, co-digestion also has limitations, such as high effluent COD concentrations and additional pretreatment requirements [25]. An alternative method incorporated in the biodigester system could be the application of modified iron nanoparticles (NPs) to the co-digestion of wastes. However, current literature provides limited information.

While only three recent studies have begun to look at the influence of metal nanoparticles in either $\mathrm{AD}$ of manure [10] or in waste activated sludge [11,30], no studies have systematically investigated the influence of modified iron NPs on anaerobic co-digestion of organic wastes into biogas and methane production. Research is required to better understand how iron NPs interact not only with methanogens but also with all other microbial groups and how iron NPs influence biogas production of the co-digestion process, since organic wastes are commonly utilized as biomass in the $\mathrm{AD}$ process. It is hypothesized that the accumulation of volatile fatty acids (VFAs) is increased by the addition of iron additives, thereby reducing $\mathrm{pH}$; this may inhibit the methanogenesis, since the addition of organic wastes may offer more substrates for methanogenesis. Additionally, in the $\mathrm{AD}$ of complex residues, it is often observed that hydrolysis is the limiting step. Factors that affect hydrolysis on addition of iron additives warrant further investigation. Future research is also suggested regarding the potential influence of different types of iron additives on the initial hydrolysis step. The nature of iron additives in terms of their physicochemical properties such as size, surface area, shape, polymorphs, and the types of metallic nanoparticles could also affect the overall performance of the $\mathrm{AD}$ process.

The addition of iron NPs could eliminate $\mathrm{pH}$ reduction and alleviate high COD concentration in the effluent. The extent and kinetics of biogas production of modified iron NPs are a function of the surface reactivity, which depends on the physicochemical properties of different types of iron NPs. The relative importance of enhancing biogas may depend on not only the properties of the NP surface but also compositions of biomass. For instance, biosolids as one of the types of biomass may yield different amounts of biogas under the same operation conditions compared to co-digestion of organic waste compositions. Even different types of biosolids (Class A versus Class B) may influence the efficacy of AD performance in terms of the production of biogas, since Class B biosolids 
that contain a higher level of detectable pathogens may inhibit digestion of biomass in the $\mathrm{AD}$ biodigester.

In an anaerobic digestion system, iron additives may stimulate interactions of organic substrates with methanogens to produce biogas through the methanogens' biostimulating mechanisms on the co-digestion of organic wastes $[10,11,30-34]$. The availability of surfaces may also enhance microbial activity. Studies are strongly encouraging for increasing biogas production by the addition of modified iron NPs to a co-digestion system. The addition of iron additives may serve as a catalyst to enhance the AD process for substrates with varied compositional characteristics.

Interactions and Roles of Iron NPs on Acetotrophic and Hydrogenotrophic Methanogens during $\mathrm{AD}$ Conversion of Biomass to Methane

Research on the interactions of modified iron NPs with acetotrophic and hydrogenotrophic methanogens and how they play a critical role in the last step of methanogenesis could provide insight into the reaction mechanisms that occur between iron additives and organic substrates in a biodigester system. Studies dispute the effects of trace elements on biogas and methane production. For instance, Demirel and Scherer [9] indicated that trace metals are imperative for the performance and stability of biogas production in digesters operated with biomass composed of organic fractions of solid wastes or other types of organic waste. Another study indicated that the $\mathrm{AD}$ of food waste using trace metal solutions including $\mathrm{Fe}, \mathrm{Zn}, \mathrm{Cu}$, and Mo showed increased production of $\mathrm{CH}_{4}$ up to $8 \%$ and $15 \%$ increases in biogas production [35]. Such enhancement through the addition of trace nutrients was also found in other studies $[36,37]$.

On the other hand, several studies showed inhibitory effects by NPs composed of $\mathrm{ZnO}, \mathrm{CuO}, \mathrm{Mn}_{2} \mathrm{O}_{3}, \mathrm{Cr}_{2} \mathrm{O}_{3}$ etc. due mainly to oxidative stress responses and membrane damage [6,31-33,38-44]. Nonetheless, there is little data or information on reaction mechanisms responsible for the effect of trace element requirements in the $\mathrm{AD}$ process fed with organic fractions of municipal solid waste [9]. Moreover, neither information nor scientific knowledge on the reaction pathways of iron NPs with methanogens is available.

Studies that cover the role of iron NPs on both acetotrophic and hydrogenotrophic methanogens of particulate solid biomass for biogas and methane production are scarce. It is hypothesized that the different types of iron NPs influence methane formation in AD. Such effects may depend on electron release and hydrogen generation, which can lead to accelerated methanogenic reactions under anaerobic condition as follows, in addition to other possible effects due to physicochemical properties such as surface morphologies and size.

Proposed reactions involving iron NPs in the AD system are as follows:

$$
\begin{aligned}
& \mathrm{Fe}^{0} \rightarrow \mathrm{Fe}^{2+}+2 \mathrm{e}^{-} \\
& 4 \mathrm{Fe}^{0}+8 \mathrm{H}^{+}+\mathrm{CO}_{2} \rightarrow \mathbf{4} \mathrm{Fe}^{2+}+\mathrm{CH}_{4}+2 \mathrm{H}_{2} \mathrm{O} \\
& \mathrm{Fe}^{0}+2 \mathrm{H}_{2} \mathrm{O} \rightarrow \mathrm{Fe}^{2+}+\mathrm{H}_{2}+2 \mathrm{OH}^{-} \\
& 4 \mathrm{H}_{2}+\mathrm{CO}_{2} \rightarrow \mathrm{CH}_{4}+2 \mathrm{H}_{2} \mathrm{O} \\
& \mathrm{CH}_{3} \mathrm{COOH} \rightarrow \mathrm{CH}_{4}+\mathrm{CO}_{2} \\
& \mathrm{HCO}_{2} \mathrm{H} \rightarrow \mathrm{CO}_{2}+\mathrm{H}_{2} \\
& 4 \mathrm{H}_{2}+2 \mathrm{CO}_{2} \rightarrow \mathrm{CH}_{3} \mathrm{COO}^{-}+\mathrm{H}^{+}+2 \mathrm{H}_{2} \mathrm{O} \\
& \mathrm{CH}_{3} \mathrm{COO}^{-}+\mathrm{H}^{+} \rightarrow \mathrm{CH}_{4}+\mathrm{CO}_{2}
\end{aligned}
$$

Zero-valent iron releases two electrons upon oxidation to ferrous iron (reaction 1). Electron release from metallic particles (iron particles as one of the examples) offers anaerobic conditions that favor hydrogenation pathways to consumer $\mathrm{CO}_{2}$ and thus production of methane. The electrons released by iron NPs can be consumed by inorganic $\mathrm{CO}_{2}$, thereby promoting $\mathrm{CH}_{4}$ (reaction 4) or by acids (e.g., acetic acid) (reaction 5). Dehydrogenation through the decomposition of formic acid (one of the major byproducts from biomass) can result in the formation of $\mathrm{CO}_{2}$ and $\mathrm{H}_{2}$ (reaction 6) [34]. Hydrogenation pathways can be accelerated by iron under the anaerobic condition (reaction 3 ) and thus produce more methane (reaction 4). In addition, iron NPs can serve as a catalyst to remove toxic compounds that may hinder microbial activities (e.g. $\mathrm{Fe}^{0}+\mathrm{H}_{2} \mathrm{~S} \rightarrow \mathrm{FeS}+\mathrm{H}_{2}$ ) [45]. Figure 1 is a schematic diagram that illustrates the addition of iron additives to $\mathrm{AD}$ of biomass to produce biogas.
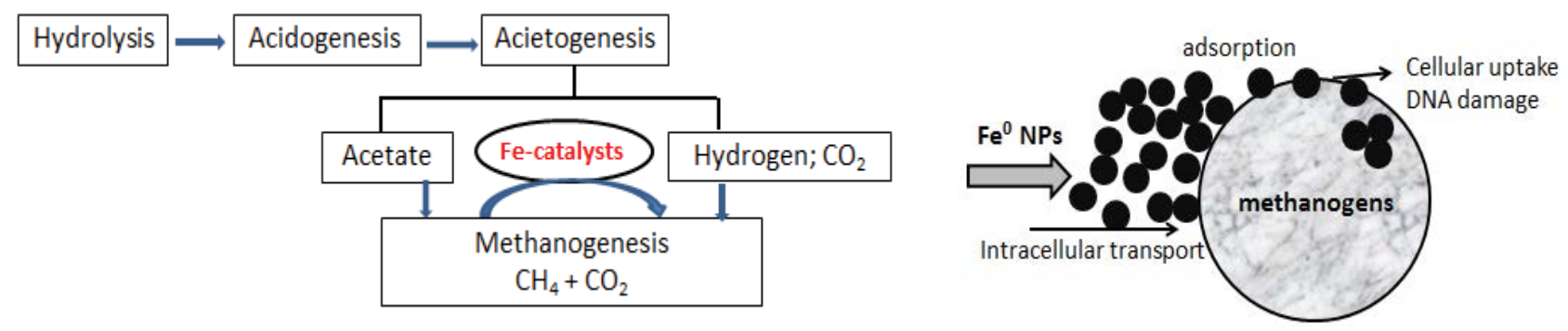

Figure 1: Schematic diagram of modified iron NP-AD of biomass to biogas. 


\section{Future Research Needs and Directions}

Given the aforementioned discussion and perspective of catalytic enhancement of biogas by iron additives in the $\mathrm{AD}$ co-digestion system, future research needs, and directions are drawn as follows.

First, the role of modified iron NPs mixed with organic substrates in $\mathrm{AD}$ needs to be examined in depth, particularly how different types of iron additives influence the performance of $\mathrm{AD}$ co-digestion with the fundamental reaction mechanism. Second, characterization of iron NP modification before and after exposure to co-digestion of biomass would be valuable, since the extent of catalytic increase of biogas in an $\mathrm{AD}$ co-digestion system may depend on different types of iron NPs (e.g., green tea-extracted iron NPs, shotblast dust, and waste iron). Such a characterization study is also essential to elucidating the effect of modified iron NPs on bioenergy and their role in methanogenesis of AD.

A study on the effect of different dosages of modified iron NPs on biogas production over fermentation times is essential. Particularly, research is encouraged to involve the biogas and methane production kinetics by modified iron NPs on cow manure of $\mathrm{AD}$ as a function of different dosages and types of iron NPs over fermentation times. Assessing the methanogenic activity is another future study direction, which could be performed by analyzing the composition of biomass to identify any influence of iron additives on the production of methane. Iron NPs, as other types of NPs, should have electrostatic interactions. High specific areas of the iron NPs may be attributed to the cellular uptake of NPs inside the methanogens. Transmission electron microscope (TEM) analyses will provide such insight prior to beginning more in-depth studies. Several studies [31,46-48] have investigated the stimulating effects of NPs on the cellular uptake inside the methanogens by NPs in sludge digestion. These studies indicated that NP sizes have a strong effect on the binding and activation of membrane receptors and their resultant protein appearance. A recent study [10] also indicated consistent results with increasing biogas and methane improvement through the spherical shape of magnetic NP additives. As briefly discussed previously, different types of iron NPs that have different surface morphologies and sizes may alter the breakdown of biomass by interacting with methanogens in the $\mathrm{AD}$ system to produce biogas and methane.

Investigating a microorganism community of inoculum after exposure to modified iron NPs would aid in exploring any changes in methanogens using advanced biology tools by employing fluorescent in situ hybridization (FISH) and fluorescent quantitative polymerase chain reaction (FQ-PCR). NPs should be adsorbed onto manure surfaces after long-term the surfaces' exposure to the NPs, possibly due to electrostatic interactions and the high specific area of the NPs. FISH and confocal laser-scanning microscopy (CLSM) can identify the primary cow manure components in the absence of iron NPs and any changes/shifts of the microorganism components after exposure to various types of iron NPs at various concentrations $(0,5,10$, and $20 \mathrm{mg} / \mathrm{L})$. Real-time FQ-PCR assays can be used to further examine how different dosages at different types of iron NPs affect the abundance of methanogens in an $\mathrm{AD}$ process.

Lastly, investigating the role of iron NPs as a catalyst for an interspecies electron transfer (IET) mechanism of acetrotropic and hydrogenotrophic methanogens is another research direction to be taken in the future. Such a study would be valuable in exploring whether different types of iron NPs can serve as a catalyst for the IET pathway among the two important acetotrophic and hydrogenotrophic methanogens. Scanning electron microscopy (SEM)/TEM images of methanogens (each methanogen and mixed methanogens) formed in the absence and presence of different types of iron NPs (e.g., cell surfaces vs. cell-attaching iron NPs), along with EDS and Malvern Zetasizer, could assist in the identification of any changes in morphology, aggregation, size distribution, and chemical compositions. As discussed earlier, iron plays a critical role as an electron donor and is assumed to be one of the critical factors in the reaction pathways that enhance biogas and methane production. The extent to which iron-released electrons are transferred among methanogens and whether there are any inhibiting effects due to the presence of biomass byproducts (acetate, formate, and ammonia nitrogen) during $\mathrm{AD}$ fermentation are unclear. Moreover, there is a literature gap in terms of quantitative information regarding cumulative electrons transferred from iron NPs to methanogens.

In conclusion, all the suggested research directions are significant, given that such crucial information can affect the ability of waste-disposal and wastewater-treatment industries as well as the research society and community's ability to identify an environmentally sound approach to the conventional AD system, which involves utilizing waste as either a resource or a non-toxic chemical addition (i.e. green tea-extracted iron) to the AD system. A potential pitfall may need to be addressed concerning the aggregation effect from some of the iron NPs (e.g., steel-industry byproducts and waste iron), because aggregation might affect the overall performance of modified iron NPs. To address such a potential issue, research is suggested on coating iron NPs with stabilizers to examine the effect of coating materials on the overall efficiency of the AD process in production of biogas and the decomposition of organic substrates.

\section{References}

1. Zhang P, Zeng G, Zhang G, Li Y, Zhang B, et al. (2008) Anaerobic co-digestion of biosolids and organic fraction of 
municipal solid waste by sequencing batch process. Fue Processing Technology 89: 485-489.

2. Steuteville R (1995) The state of garbage in America. BioCycle 4: 54-63.

3. Williams ME (1994) Intergrated Solid Waste Management. In: F Kreith, Handbook of Solid Waste Management. McGraw-Hill Inc, New York.

4. Tchobanoglous, H Theisen, S Vigil (1993) Integrated Solid Waste Management. McGraw-Hill Inc, New York.

5. Fricke K, Santen H, Wallmann R, Hüttner A, Dichtl N (2007) Operating problems in anaerobic digestion plants resulting from nitrogen in MSW. Waste Management 27: 30-43.

6. Chen JL, Ortiz R, Steele TW, Stuckey DC (2014) Toxicants inhibiting anaerobic digestion: a review. Biotechnology Advances 32: 1523-1534.

7. Paulo LM, Stams AJ, Sousa DZ (2015) Methanogens, sulphate and heavy metals: A complex system. Reviews in Environmental Science and Bio/Technology 14: 537-553.

8. Gerardi MH (2003) The Microbiology of Anaerobic Digester. John Wiley \& Sons.

9. Demirel B, Scherer P (2011) Trace element requirements of agricultural biogas digesters during biological conversion of renewable biomass to methane. Biomass and Bioenergy 35: 992-998.

10. Bdelsalam E, Samer M, Attia YA, Abdel-Hadi MA, Hassan $\mathrm{HE}$, et al. (2017) Influence of zero valent iron nanoparticles and magnetic iron oxide nanoparticles on biogas and methane production from anaerobic digestion of manure. Energy 120: $842-853$.

11. Wang T, Zhang D, Dai L, Chen Y, Dai X (2016) Effects of metal nanoparticles on methane production from waste-activated sludge and microorganism community shift in anaerobic granular sludge. Scientific Reports 6: 25857.

12. Yang Z, Shi X, Wang C, Wang L, Guo R (2015) Magnetic nanoparticles facilitate methane production from ethanol via acting as electron acceptors. Scientific Reports 5: 16118.

13. Huang L, Weng X, Chen Z, Megharaj M, Naidu R (2014) Green synthesis of iron nanoparticles by various tea extracts: Comparative study of the reactivity. Spectrochimia Acta Part A: Molecular and Biomolecular Spectroscopy 130: 295-301.

14. Huang L, Weng X, Chen Z, Megharaj M, Naidu R (2014) Synthesis of iron-based nanoparticles using oolong tea extract for the degradation of malachite green. Spectrochimica Acta Part A: Molecular and Biomolecular Spectroscopy 117: 801-804.

15. Wang T, Jin X, Chen Z, Megharaj M, Naidu R (2014) Green synthesis of Fe nanoparticles using eucalyptus leaf extracts for treatment of eutrophic wastewater. Science of the Total Environment 466: 210-213.

16. Wu K, Xie Y, Zhao J, Hidaka H (1999) Photo-Fenton degradation of a dye under visible light irradiation. Journal of Molecular Catalysis A: Chemical 144: 77-84.

17. Hachem C, Bocquillon F, Zahraa O, Bouchy M (2001) Decolourization of textile industry wastewater by the photocatalytic degradation process. Dyes and Pigments 49: 117-125.

18. Yatome C, Yamada S, Ogawa T, Matsui M (1993) Degradation of crystal violet by Nocardia corallina. Applied Microbiology and Biotechnology 38: 565-569.
19. Nadagouda MN, Castle AB, Murdock RC, Hussain SM, Varma RS (2010) In vitro biocompatibility of nanoscale zerovalent iron particles (NZVI) synthesized using tea polyphenols. Green Chemistry 12: 114-122.

20. Smuleac V, Varma R, Sikdar S, Bhattacharyya D (2011) Green synthesis of $\mathrm{Fe}$ and Fe/Pd bimetallic nanoparticles in membranes for reductive degradation of chlorinated organics. Journal of Membrane Science 379: 131-137.

21. Chen ZX, Jin XY, Chen Z, Megharaj M, Naidu R (2011) Removal of methyl orange from aqueous solution using bentonite-supported nanoscale zero-valent iron. Journal of Colloid and Interface Science 363: 601-607.

22. Shahwan T, Sirriah SA, Nairat M, Boyacı E, Eroğlu AE, et al. (2011) Green synthesis of iron nanoparticles and their application as a Fenton-like catalyst for the degradation of aqueous cationic and anionic dyes. Chemical Engineering Journal 172: 258-266.

23. Hoag GE, Collins JB, Holcomb JL, Hoag JR, Nadagouda MN, et al. (2009) Degradation of bromothymol blue by 'greener'nano-scale zero-valent iron synthesized using tea polyphenols. Journal of Materials Chemistry 19: 8671-8677.

24. Wu W (2007) Anaerobic co-digestion of biomass for methane production: Recent research achievements. Optimization, 1, 1VS.

25. Braun R, Wellinger A (2003) Potential of co-digestion. In: IEA Bioenergy, Task 37.

26. Mata-Alvarez J, Mace S, Llabres P (2000) Anaerobic digestion of organic solid wastes. An overview of research achievements and perspectives. Bioresource Technology 74: 3-16.

27. Desai M, Patel V, Madamwar D (1994) Effect of temperature and retention time on biomethanation of cheese whey-poultry waste-cattle dung. Environmental Pollution 83: 311-315.

28. Murto M, Björnsson L, Mattiasson B (2004) Impact of food industrial waste on anaerobic co-digestion of sewage sludge and pig manure. Journal of Environmental Management 70: 101-107.

29. Lehtomäki A, Huttunen S, Rintala JA (2007) Laboratory investigations on co-digestion of energy crops and crop residues with cow manure for methane production: Effect of crop to manure ratio. Resources, Conservation and Recycling 51: 591-609.

30. Suanon F, Sun Q, Li M, Cai X, Zhang Y, et al. (2017) Application of nanoscale zero valent iron and iron powder during sludge anaerobic digestion: Impact on methane yield and pharmaceutical and personal care products degradation. Journal of Hazardous Materials 321: 47-53.

31. Mu H, Chen $\mathrm{Y}$, Xiao N (2011) Effects of metal oxide nanoparticles $\left(\mathrm{TiO}_{2}, \mathrm{Al}_{2} \mathrm{O}_{3}, \mathrm{SiO}_{2}\right.$ and $\left.\mathrm{ZnO}\right)$ on waste activated sludge anaerobic digestion. Bioresource Technology 102: 10305-10311.

32. Yang Y, Zhang C, Hu Z (2013) Impact of metallic and metal oxide nanoparticles on wastewater treatment and anaerobic digestion. Environmental Science: Processes \& Impacts 15: 39-48.

33. $\mathrm{Mu} \mathrm{H}$, Chen $\mathrm{Y}$ (2011) Long-term effect of $\mathrm{ZnO}$ nanoparticles on waste activated sludge anaerobic digestion. Water Research 45: 5612-5620.

34. Bdelsalam A, Loges B, Gärtner F, Torborg C, Fumino K, et al. (2010) Iron-catalyzed hydrogen production from formic 
acid. Journal of the American Chemical Society 132: 8924 8934.

35. Lane AG (1984) Laboratory scale anaerobic digestion of fruit and vegetable solid waste. Biomass 5: 245-259.

36. Rivard CJ, Vinzant TB, Adney WS, Grohmann K, Himmel ME (1990) Anaerobic digestibility of two processed municipal-solid-waste materials. Biomass 23: 201-214.

37. Kayhanian M, Rich D (1995) Pilot-scale high solids thermophilic anaerobic digestion of municipal solid waste with an emphasis on nutrient requirements. Biomass and Bioenergy 8: 433-444.

38. Kaweeteerawat $\mathrm{C}$, Ivask $\mathrm{A}$, Liu $\mathrm{R}$, Zhang $\mathrm{H}$, Chang $\mathrm{CH}$, et al. (2015) Toxicity of metal oxide nanoparticles in Escherichia coli correlates with conduction band and hydration energies. Environ Sci Technol 49: 1105-1112.

39. Choi O, Deng KK, Kim NJ, Ross L, Surampalli RY, et al (2008) The inhibitory effects of silver nanoparticles, silver ions, and silver chloride colloids on microbial growth. Water Research 42: 3066-3074.

40. Brar SK, Verma M, Tyagi RD, Surampalli RY (2010) Engineered nanoparticles in wastewater and wastewater sludge-Evidence and impacts. Waste Management 30: 504-520.

41. Eduok S, Martin B, Villa R, Nocker A, Jefferson B, et al.
(2013) Evaluation of engineered nanoparticle toxic effect on wastewater microorganisms: Current status and challenges. Ecotoxicology and Environmental Safety 95: 1-9.

42. Stasinakis AS (2012) Review on the fate of emerging contaminants during sludge anaerobic digestion. Bioresour Technol 121: 432-440.

43. Kaegi R, Voegelin A, Sinnet B, Zuleeg S, Hagendorfer $H$, et al. (2011) Behavior of metallic silver nanoparticles in a pilot wastewater treatment plant. Environ Sci Technol 45: 3902-3908.

44. Jin RC, Yang GF, Yu JJ, Zheng P (2012) The inhibition of the Anammox process: a review. Chemical Engineering Journal 197: 67-79.

45. Li XQ, Brown DG, Zhang WX (2007) Stabilization of biosolids with nanoscale zero-valent iron (nZVI). Journal of Nanoparticle Research 9: 233-243.

46. Verma A, Stellacci $F$ (2010) Effect of surface properties on nanoparticle-cell interactions. Small 6: 12-21.

47. Jiang W, Kim BY, Rutka JT, Chan WC (2008) Nanoparticle-mediated cellular response is size-dependent. Nature Nanotechnology 3: 145-150.

48. Nel AE, Mädler L, Velegol D, Xia T, Hoek EM, et al. (2009) Understanding biophysicochemical interactions at the nano-bio interface. Nature Materials 8: 543-557. 